\title{
Estudo preliminar sobre a influência do teor de enxofre do combustível na emissão de amônia em motociclos e veículos leves dos ciclos Otto e Diesel.
}

\author{
Luiz Carlos Daemme ${ }^{1}$, Renato de Arruda Penteado Neto ${ }^{1}$, Marcelo Risso Errera ${ }^{2}$, Fátima M. \\ Z. Zotin ${ }^{3}$ \\ ${ }^{1}$ Instituto de Tecnologia para o Desenvolvimento - LACTEC; ${ }^{2}$ Universidade Federal do \\ Paraná (UFPR), ${ }^{3}$ Universidade do Estado do Rio de Janeiro (UERJ).
}

E-mails: Luiz.carlos@ lactec.org.br, Renato@ lactec.org.br, Errera@ufpr.br, Fmzzotin@gmail.com.

\section{RESUMO}

Devido às restrições ambientais mundiais, o controle das emissões veiculares torna-se cada vez mais rigoroso. Os limites de emissões vêm sendo sensivelmente reduzidos e o papel das emissões não regulamentadas está tornando-se cada vez mais importante. As emissões de amônia têm recebido especial atenção por esse composto contribuir com a produção de material particulado secundário na forma de nitratos $\left(\mathrm{NH}_{4} \mathrm{NO}_{3}\right)$ ou sulfatos de amônia $\left(\left(\mathrm{NH}_{4}\right)_{2} \mathrm{SO}_{4}\right)$. A amônia é o terceiro maior composto nitrogenado na atmosfera. O objetivo da presente pesquisa foi avaliar a influência do teor de enxofre do combustível nacional na emissão de amônia em uma amostra de seis veículos (três motociclos, um veículo do ciclo Otto e dois veículos do ciclo diesel). Os testes foram conduzidos de acordo com as normativas brasileiras, utilizando-se de diesel contendo 6 e 400 ppm de enxofre e gasolinas contendo 30 e $320 \mathrm{ppm}$ de enxofre. Ambas as gasolinas possuíam teor de $22 \%$ de etanol anidro. Os resultados demonstram que para o veículo do ciclo Otto, equipado com catalisador de três vias, a redução do teor de enxofre gera uma tendência de incremento na emissão de amônia. Nos motociclos foi observada a mesma tendência. Quanto aos veículos comerciais leves do ciclo Diesel, não foi observada influência significativa do teor de enxofre sobre as emissões de amônia.

\section{INTRODUÇÃO}

O crescente desenvolvimento da indústria exige um aumento da demanda por combustíveis que, ao serem queimados, causam danos ao meio ambiente e à saúde pública [1]. As emissões veiculares são a principal fonte de poluição nos grandes centros urbanos, sendo o seu controle vital para o bem estar da população [2].

No Brasil, essa preocupação não é recente. Em 1986 o CONAMA instaurou um programa para redução progressiva dos limites de emissões veiculares provenientes de veículos automotores leves e pesados (PROCONVE) [3], sendo esse modelo implantado posteriormente para os motociclos com a criação do PROMOT, em 2002 [4]. 
A redução dos limites de emissões exige uma constante evolução das tecnologias automotivas, sendo que vários aspectos contribuem para que os referidos limites sejam atendidos. Dentre eles se destacam a tecnologia de controle de emissões do veículo; as condições de operação e manutenção do motor e do catalisador, as características dos combustíveis, e a temperatura ambiente. No que diz respeito ao combustível, vários estudos têm sido realizados utilizando diversos tipos de formulações e tecnologias com foco nas emissões legisladas, porém informações de estudos sobre os impactos nas emissões não regulamentadas são escassas [5][6].

Com relação ao teor de enxofre, diversos países vêm aplicando em suas legislações limitações visando à redução da emissão de $\mathrm{SO}_{2}$ e proporcionando uma otimização da eficiência dos catalisadores. Na gasolina comercial brasileira, a legislação, que atualmente admite uma concentração de até 800 ppm, exigirá uma redução para no máximo 50 ppm já a partir de 2014. Para o diesel, em que até recentemente eram admitidos teores de 1800 ppm para cidades do interior e 500 ppm para metrópoles, a partir de 2013 os teores estão limitados a 500ppm no interior e apenas 10 ppm nas metrópoles.

No processo de queima, o enxofre do combustível é oxidado a $\mathrm{SO}_{2}$, interagindo com a superfície dos catalisadores e interferindo na conversão de poluentes regulamentados, como $\mathrm{NO}_{\mathrm{X}}, \mathrm{CO}$ e hidrocarbonetos [6][7]. Os catalisadores de três vias têm a função de transformar esses poluentes em $\mathrm{CO}_{2}, \mathrm{H}_{2} \mathrm{O}$ e $\mathrm{N}_{2}$, reduzindo drasticamente as emissões veiculares. Em contrapartida, estudos indicam que as complexas reações químicas que ocorrem durante sua operação geram compostos não regulamentados, como $\mathrm{NH}_{3}$ e $\mathrm{N}_{2} \mathrm{O}$ e $\mathrm{H}_{2}$ [7][8] e que combustíveis com baixos teores de enxofre tendem a aumentar a emissão de amônia no gás de escapamento nos veículos do ciclo Otto dotados de catalisadores de três vias [6] [7][9].

Artigos relatam ainda que a emissão de amônia cresce diretamente com a severidade do ciclo de condução ao qual o veículo é submetido em testes de laboratório [10]. Ainda, nos catalisadores de três vias, sua formação se dá em certas condições, como a relação ar/combustível (lambda) menor que 1 e após o catalisador atingir o light-off [11].

O presente artigo dedica especial atenção à amônia, considerado o terceiro gás nitrogenado, em concentração, mais abundante na atmosfera, cujas principais fontes de emissão são a agricultura e fontes naturais. É um dos principais contribuintes para os processos de acidificação e eutrofização em lagos [12][13]. Nos centros urbanos, a principal fonte de amônia são as emissões automotivas. É classificada como poluente tóxico, podendo causar impactos diretos à saúde pública. Uma das maiores preocupações da emissão de amônia proveniente de fontes móveis é a possibilidade de sua reação com ácido sulfúrico ou nítrico, contribuindo com a formação de material particulado secundário $\left(\mathrm{PM}_{2.5}\right)$ na forma de nitrato de amônia $\left(\mathrm{NH}_{4} \mathrm{NO}_{3}\right)$ ou sulfato de amônia $\left(\left(\mathrm{NH}_{4}\right) 2 \mathrm{SO}_{4}\right)$ [5][9][14].

Como as partículas formadas são menores que $2,5 \mu \mathrm{m}$, não são retidas nos mecanismos naturais existentes no trato superior respiratório e chegam até os pulmões, provocando danos à saúde do homem. Por outro lado, a amônia pode agir como composto capaz de tamponar, em determinada extensão, a acidez provocada por gases e partículas da atmosfera, em reações com ácidos atmosféricos oriundos da oxidação do $\mathrm{SO}_{2}$ e $\mathrm{NO}_{\mathrm{X}}$ gerando, como produto final, sais de amônio, na forma de material particulado. Desta forma, o aumento da amônia gasosa na atmosfera pode, por um lado, atenuar a acidez atmosférica e, por outro, favorecer o aumento na concentração de partículas inaláveis e assim agravar o risco a saúde humana. 
A interferência do homem vem provocando perturbações nas concentrações naturais deste composto na atmosfera, e devido à complexidade do tema, não existem ainda estudos que possam mensurar as consequências desses efeitos no ambiente [15].

A formação de amônia é atribuída às reações de óxido nítrico com gás hidrogênio produzido a partir de uma reação de deslocamento da água e gás entre $\mathrm{CO}$ e água.

$\mathrm{CO}+\mathrm{H}_{2} \mathrm{O} \rightarrow \mathrm{CO}_{2}+\mathrm{H}_{2}$ Equação 01

O hidrogênio produzido na reação 1 reage com o óxido de nitrogênio existente no gás de escapamento e produz a amônia:

$$
\begin{aligned}
& 2 \mathrm{NO}+2 \mathrm{CO}+3 \mathrm{H}_{2} \rightarrow 2 \mathrm{NH}_{3}+2 \mathrm{CO}_{2} \\
& 2 \mathrm{NO}+5 \mathrm{H}_{2} \rightarrow 2 \mathrm{NH}_{3}+2 \mathrm{H}_{2} \mathrm{O}
\end{aligned}
$$

No que diz respeito a veículos do ciclo Otto, Centeno et al.[7], verificaram em seu estudo que a emissão de amônia é maior em veículos equipados com catalisador de três vias. Em sua pesquisa, utilizando-se de uma bancada para testes em catalisadores, sob condições estáticas, equivalente a um veículo em velocidade de $120 \mathrm{~km} / \mathrm{h}$ e temperatura dos gases de exaustão de $500^{\circ} \mathrm{C}$, os autores demonstraram, com uma variação do teor de enxofre de $0-50 \mathrm{ppm}$, o comportamento das emissões de $\mathrm{NH}_{3}$ e $\mathrm{N}_{2} \mathrm{O}$. Para a detecção dos compostos presentes nos gases foi utilizada a técnica de FTIR. Conforme FIGURA 1, é possível observar que sob as mesmas condições, variando apenas o teor de enxofre, as emissões de $\mathrm{NH}_{3}$ e $\mathrm{N}_{2} \mathrm{O}$ têm comportamento oposto (inverso), sendo que a emissão de amônia é reduzida com aumento do teor de enxofre.

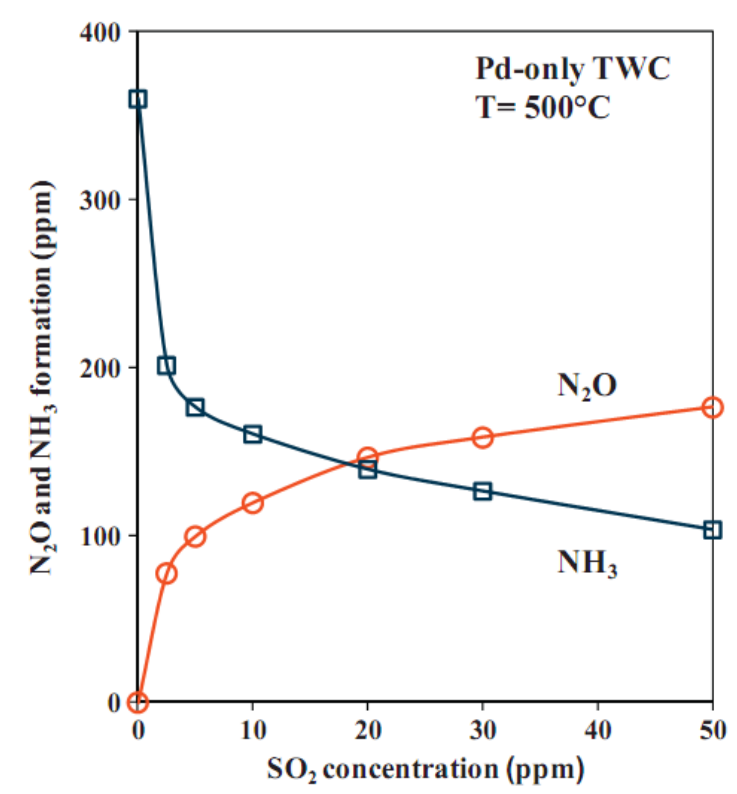

FIGURA 1: Relação entre as emissões de $\mathrm{NH}_{3}$ e $\mathrm{N}_{2} \mathrm{O}$ com o teor de enxofre, usando um catalisador TWC à base de $\mathrm{Pd}$, em condições ricas: 2100 ppm de NO, 515 ppm de $\mathrm{C}_{3} \mathrm{H}_{8}, 2200$ ppm de $\mathrm{H}_{2}, 6600$ ppm de $\mathrm{CO}$, $10 \%$ (v/v) de $\mathrm{H}_{2} \mathrm{O}$ e $0,53 \%$ (v/v) de $\mathrm{O}_{2}$, com teores de $\mathrm{SO}_{2}$ variando de 0 a 50 ppm. Razão A/F = 14,60. Fonte: CENTENO et al. [7].

Quanto à correlação entre emissão de amônia e as emissões regulamentadas, foi observado por Livinsgston et al. [14] uma fraca correlação entre emissão de $\mathrm{CO}$ e $\mathrm{NH}_{3}(\mathrm{R}=0.56)$. Neste 
estudo os pesquisadores observaram que uma maior emissão de amônia ocorre em ciclos mais agressivos de dirigibilidade (por exemplo, para ciclo americano US06). Relataram também que, com o envelhecimento do catalisador, ocorre uma tendência de aumento das emissões de $\mathrm{CO}$ e $\mathrm{NO}_{\mathrm{X}}$, com redução na produção de amônia. O fator de emissão encontrado no estudo foi de $46 \mathrm{mg} / \mathrm{km}$ de amônia, sendo ensaiados 41 veículos, totalizando 121 testes em dinamômetro de chassi. A técnica utilizada para detecção da amônia foi a de espectroscopia na região do infravermelho com transformada de Fourier (FTIR) [14].

No estudo publicado por Durbin et al. [16], em 2004, foram ensaiados doze veículos nos ciclos FTP75 e US06 usando gasolinas com 5, 30 e $150 \mathrm{ppm}$ de enxofre. Os resultados mostraram que o teor de enxofre não alterou as emissões de amônia durante ensaios no ciclo FTP75. Por outro lado, no ciclo US06, que possui condições mais severas de velocidades e acelerações, as emissões de amônia foram superiores às encontradas no ciclo FTP, aumentando com o aumento do teor de enxofre no combustível. O trabalho cita artigos com diferentes tendências quanto à influência do enxofre na emissão de amônia.

No que tange a motociclos, os artigos apresentados por Daemme et al. [17][18] demonstram que as emissões de amônia nos gases de escapamento de motociclos equipados com catalisadores de três vias são expressivas. Nas pesquisas foram realizadas coletas dos gases de escapamento antes e após o catalisador, utilizando-se da técnica de FTIR, sendo constatada a

formação de amônia no interior do catalisador de três vias. Nestes estudos, os testes foram realizados em banco de ensaio com dinamômetro de chassis, de acordo com a regulamentação adotada pelo CONAMA para homologação de motociclos no Brasil, utilizando-se de combustíveis de referência para ensaios de emissões veiculares.

No entanto, existe escassez de resultados que indiquem a influência combinada de diferentes teores de enxofre e uso de misturas de gasolina/ etanol, configuração típica do combustível usado no Brasil. Da mesma maneira, informações com uso de teores de biodiesel não são comentadas.

O objetivo do presente artigo foi apresentar o impacto do teor de enxofre no combustível brasileiro sobre as emissões de amônia em veículos automotores do ciclo Otto (veículos leves de passageiros e motociclos) e do ciclo Diesel (veículos comerciais leves), utilizando veículos com diferentes tecnologias e condições de uso.

\section{METODOLOGIA}

Para realização da presente pesquisa foram utilizados 6 veículos automotores, possuindo diferentes tecnologias e condições de uso, com intuito de se observar em um cenário macro a influência do teor de enxofre nas emissões de amônia. A TABELA 1 apresenta as características dos veículos utilizados nos experimentos. As amostras com identificação BK se referem a motociclos, VP a veículos leves de passageiros e CL veículos comerciais leves do ciclo Diesel. 
TABELA 1: CARACTERÍSTICAS DAS AMOSTRAS EMPREGADAS NO ESTUDO.

\begin{tabular}{ccccccc}
\hline Identificação & Motor $\left(\mathrm{cm}^{3}\right)$ & Km inicial & $\begin{array}{c}\text { Fase PROCONVE/ } \\
\text { PROMOT }\end{array}$ & $\begin{array}{c}\text { Sistema de } \\
\text { injeção }\end{array}$ & Catalisador & $\begin{array}{c}\text { Ano de } \\
\text { fabricação }\end{array}$ \\
\hline BK1 & 300 & $*$ & M 3 & EFI & 3 vias & 2010 \\
\hline BK2 & 300 & 17.853 & M 3 & EFI & 3 vias & 2011 \\
\hline BK3 & 150 & 45.306 & M 3 & EFI & 3 vias & 2009 \\
\hline VP1 & 1.000 & 125.560 & L 4 & EFI & 3 vias & 2005 \\
\hline CL1 & 3.200 & 25.552 & L 3 & BI** & DOC*** & 2004 \\
\hline CL2 & 2.800 & 10.719 & L 6 & CR** & DOC*** & 2012 \\
\hline * moto de uso exclusivo em laboratório. & & & & \\
** BI: bomba injetora alta pressão, CR: commom rail \\
*** catalisador de oxidação para veículos do ciclo Diesel.
\end{tabular}

Todos os veículos foram submetidos a um teste estático, simulando uma inspeção veicular de acordo com procedimentos descritos pelo IBAMA [19], antes da execução dos testes em dinamômetro. Os resultados obtidos na simulação demonstraram que as amostras estavam de acordo com limites de emissões para seus respectivos anos de fabricação.

Como combustíveis de teste, foram utilizados uma gasolina $\mathrm{C}$, com teor de enxofre que atende à atual especificação da ANP (máximo 800 ppm), e outra com teor inferior a 50 ppm, valor que entrará em vigor a partir de 2014. Em vista disso, esses combustíveis foram denominados "Gasolina S800" e "Gasolina S50", respectivamente. Salienta-se que ambas as gasolinas foram preparadas com um teor de etanol de $22 \%$, de modo a estar em um valor intermediário ao estabelecido na legislação, que tem variado entre 20 e $25 \%$.

De igual modo, foram utilizados dois tipos de óleo diesel. O primeiro foi chamado de "Diesel S500 e representa a composição média do diesel metropolitano que esteve em vigor até o final de 2011, com teor de enxofre máximo de 500 ppm. O outro produto foi denominado "Diesel S10", representando a nova especificação que passou a vigorar a partir de 2012. Ambos os produtos possuíam teor de biodiesel de 5\% (v/v). As TABELAS 2 e 3 apresentam algumas das propriedades dos combustíveis testados.

TABELA 2: ALGUMAS PROPRIEDADES DAS GASOLINAS ANTES DA ADIÇÃO DE 22\% DE ETANOL.

\begin{tabular}{|c|c|c|c|}
\hline \multicolumn{2}{|c|}{ Propriedades } & Gasolina S800 & Gasolina S50 \\
\hline \multirow{4}{*}{\begin{tabular}{c} 
Destilação $\left({ }^{\circ} \mathrm{C}\right)$ \\
\cline { 2 - 4 }
\end{tabular}} & $\mathrm{T} 10$ & 52,8 & 57,7 \\
\cline { 2 - 4 } & $\mathrm{T} 50$ & 93,2 & 100,2 \\
\cline { 2 - 4 } & $\mathrm{T} 90$ & 157,2 & 175,1 \\
\hline \multicolumn{2}{|c|}{ PVR $(\mathrm{kPa})$} & 196,5 & 204,1 \\
\hline \multicolumn{2}{|c|}{ Enxofre. $(\mathrm{ppm})$} & 62,1 & 48,9 \\
\hline \multirow{2}{*}{$\begin{array}{c}\text { Hidrocarbonetos } \\
(\% \mathrm{v})\end{array}$} & Aromáticos & 412 & 38 \\
\cline { 2 - 4 } & Olefínicos & 21,87 & 29,92 \\
\cline { 2 - 4 } & Saturados & 21,33 & 24,62 \\
\hline
\end{tabular}

TABELA 3: ALGUMAS PROPRIEDADES DOS DOIS TIPOS DE ÓLEO DIESEL ANTES DA ADIÇÃO DE $5 \%(\mathrm{~V} / \mathrm{V})$ BIODIESEL.

\begin{tabular}{|c|c|c|c|}
\hline \multicolumn{2}{|c|}{ Propriedades } & Diesel S500 & Diesel S10 \\
\hline \multirow{3}{*}{ Destilação $\left({ }^{\circ} \mathrm{C}\right)$} & T10 & 206,0 & 237,7 \\
\cline { 2 - 4 } & T50 & 288,2 & 291,4 \\
\cline { 2 - 4 } & T85 & 347,5 & T90=351,3 \\
\cline { 2 - 4 } & T90 & 361,0 & T95=367,1 \\
\hline \multicolumn{2}{|c|}{ Enxofre total (mg/kg), máx. } & 418 & 6 \\
\hline \multicolumn{2}{|c|}{ Ponto de Fulgor $\left({ }^{\circ} \mathrm{C}\right)$} & 50,0 & 78 \\
\hline
\end{tabular}


A condução dos ensaios em banco de chassis foi realizada conforme normativas adotadas pelo Brasil para homologação de veículos automotores, com exceção do motociclo BK1, que foi ensaiado de acordo com o novo ciclo de emissões que será adotado para essa classe de veículo automotor a partir de 2014, denominado WMTC. A TABELA 4 apresenta os ciclos e normas utilizados nos ensaios de emissões desse estudo.

TABELA 4 CICLOS DE EMISSÕES.

\begin{tabular}{ccc}
\hline Identificação & Ciclo de ensaio & Norma \\
\hline BK1 & WMTC & ECE/TRANS/180/Add.2 \\
\hline BK2 & Euro III & 97/24/EC \\
\hline BK3 & Euro III & 97/24/EC \\
\hline VP1 & FTP75 & ABNT NBR 6601 \\
\hline CL1 & FTP75 & ABNT NBR 6601 \\
\hline CL2 & FTP75 & ABNT NBR 6601 \\
\hline
\end{tabular}

O Brasil adotou como padrão de ensaios para veículos leves de passageiros, comerciais leves e motociclos a simulação em banco dinamométrico de chassis. $O$ ensaio consiste no desenvolvimento de um trajeto pré-estabelecido sobre um dinamômetro de rolos que simula as condições de carga em pista. Durante todo o trajeto as emissões de escapamento são coletadas e diluídas em ar ambiente para evitar condensação e perdas de compostos, através de um amostrador de volume constante (AVC). Parte desse gás, de maneira contínua, é armazenada em sacos amostradores de tedlar, material inerte aos compostos dos gases de escapamento. Ao final do ciclo de emissões os gases são analisados por detectores específicos. Os hidrocarbonetos foram medidos com detector de ionização de chama de hidrogênio (FID), para o metano um detector de ionização de chama equipado com coluna cromatográfica. Um detector por luminescência química foi usado nas determinações dos óxidos de nitrogênio $\left(\mathrm{NO}_{\mathrm{x}}\right)$. Analisadores de raios infravermelhos não dispersivos (NDIR) foram utilizados para determinação de $\mathrm{CO}$ e $\mathrm{CO}_{2}$. O material particulado, nos veículos do ciclo Diesel, foi quantificado por gravimetria, por meio de amostragem dos gases de escapamento em filtros específicos e posterior pesagem.

Os ensaios em veículos automotores rodoviários leves são normatizados de acordo com a ABNT NBR 6601 [20], sendo quantificadas as emissões de hidrocarbonetos, monóxido de carbono, óxidos de nitrogênio, dióxido de carbono e material particulado no gás de escapamento. O ciclo de condução, baseado no FTP 75 (Federal Test Procedure) preconizado pelo EPA (Agência Norte-Americana de Meio Ambiente) é oriundo do FTP 72, e consiste de três fases. Uma fase com partida a frio, outra transiente, realizada na sequencia da primeira. Ao final da segunda fase o veículo é desligado por dez minutos e, após, se inicia uma terceira fase com partida a quente, sendo o trajeto igual ao executado na primeira fase. A distância percorrida total é de aproximadamente 18 quilômetros, com duração de 1877 segundos, excluindo-se o tempo de parada, e velocidade média de $34,2 \mathrm{~km} / \mathrm{h}$ [21]. Na FIGURA 2 podemos observar o perfil da velocidade desenvolvida durante o ensaio de emissões. 


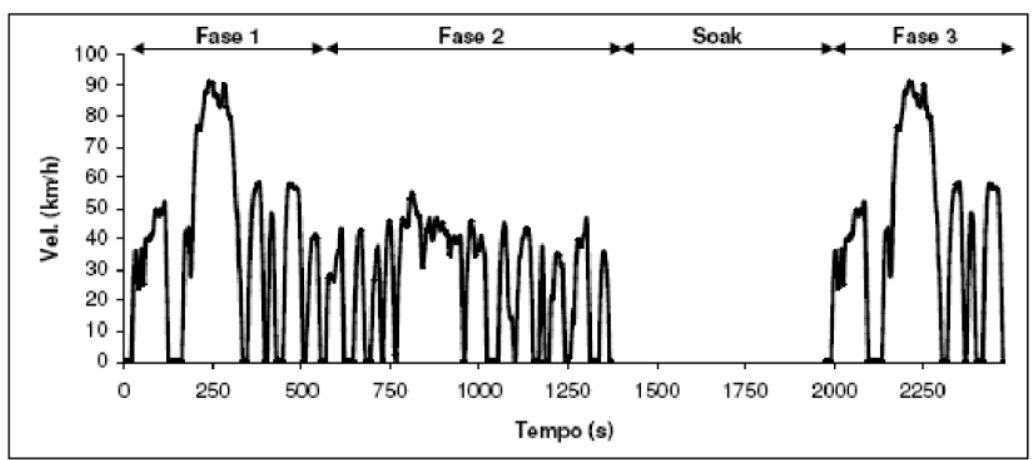

FIGURA 2: Ciclo de condução dinamométrico conforme NBR 6601. FONTE: SILVA et al.[22].

Para os motociclos, o Brasil adotou o padrão europeu de ensaios, baseando-se na normativa EC 97/24 [23], sendo regulamentadas as emissões de hidrocarbonetos totais, monóxido de carbono e óxidos de nitrogênio. O ensaio é composto de uma ou duas fases, de acordo com a cilindrada do motor do motociclo. Motores abaixo de $150 \mathrm{cc}$ realizam apenas uma fase do ensaio, denominada ciclo urbano, motociclos com motores acima de $150 \mathrm{cc}$ realizam além do ciclo urbano uma segunda fase denominada extra urbana, com velocidades que chegam a 120 $\mathrm{km} / \mathrm{h}$. As distâncias percorridas em cada fase são de aproximadamente $6,0 \mathrm{~km}$. A FIGURA 3 demonstra o perfil de velocidade em função do tempo desenvolvido durante o ensaio de emissões.

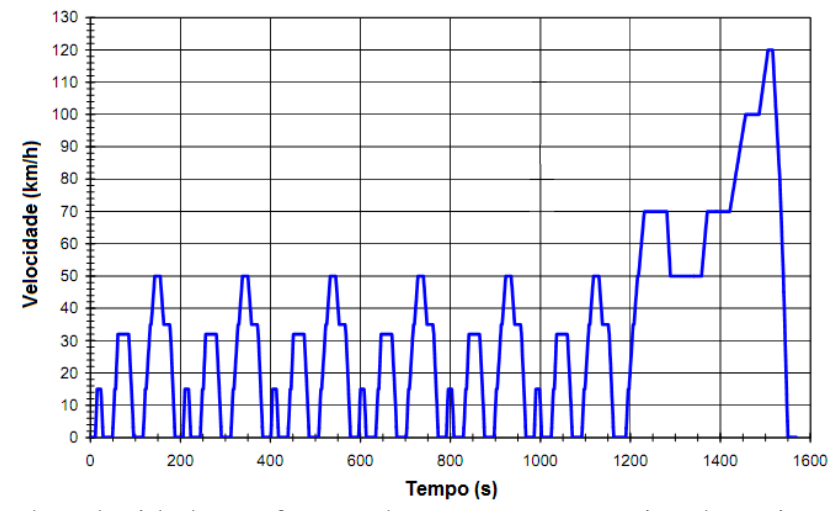

FIGURA 3: Ciclo de velocidade em função do tempo para ensaios de emissões em motociclos. FONTE: Adaptado de SAMARAS et al. [24].

A partir de 2014, de acordo com a Resolução CONAMA 432/11 [25], o Brasil estará adotando um novo ciclo para realização de ensaios de emissões em motociclos, mais representativo às condições reais de uso de uma motocicleta. Os procedimentos de ensaios para a determinação dos gases de escapamento dos motociclos, triciclos e quadriciclos passam a serem os previstos na regulamentação da Comunidade Europeia, utilizando o ciclo de condução transiente WMTC - "Worldwide Motorcycle Test Cycle" [26]. Sendo a principal diferença entre as metodologias, a característica transiente do ciclo WMTC, além do número de fases que pode ser de uma, duas ou três fases, em função da velocidade máxima desenvolvida pelo motociclo em teste combinada com a cilindrada do motor. Cada fase tem a duração de 600 s. A FIGURA 4 apresenta o ciclo completo de emissões, com três fases. 


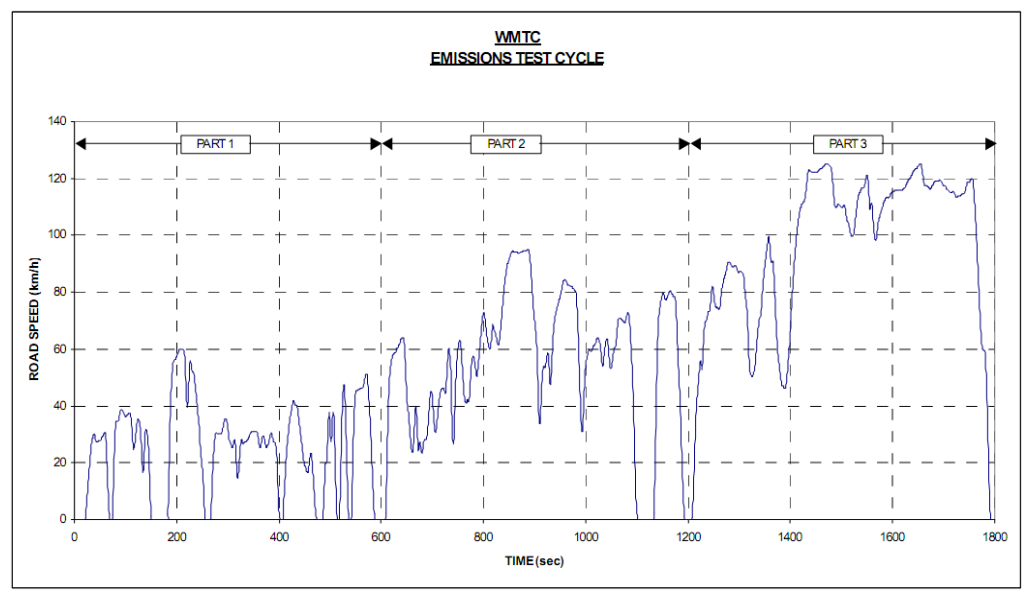

FIGURA 4: Perfil de velocidade em função do tempo - ciclo WMTC. FONTE: BOSTEELS et al. [27].

Para cada combinação veículo-combustível, em um dos testes as emissões não legisladas de $\mathrm{NH}_{3}$ foram quantificadas pela técnica de FTIR. Essa técnica que vem sendo utilizada mais recentemente no estudo das emissões veiculares desponta como importante ferramenta de estudo, sobretudo na área de emissões não regulamentadas. O equipamento usa o princípio da espectroscopia por infravermelho e se destaca pela sua capacidade de medir simultaneamente vários componentes oriundos do processo de combustão. Seu uso apresenta muitas vantagens, como rapidez das análises, medição de compostos de difícil detecção e informações das emissões em tempo real [28]. Diversos autores se utilizam dessa técnica para pesquisar as emissões de compostos não regulamentados em seus experimentos, devido a possibilidade de obtenção das emissões instantâneas, em frequências que variam de $1 \mathrm{~Hz}$ a $10 \mathrm{~Hz}$, propiciando o estudo minucioso dos fenômenos de formação dos compostos em diferentes condições e sua quantificação [29][30][31]. Pesquisas indicam forte correlação entre os resultados do FTIR e metodologias tradicionais [32], o que torna essa técnica uma alternativa atraente aos estudos das emissões não legisladas.

As emissões dos gases de exaustão direcionadas ao FTIR foram coletadas ao final do escapamento nos veículos automotores, ponto denominado pós-catalisador (tailpipe). A amostra BK1 foi instrumentada antes do catalisador e nesse ponto foram tomadas as emissões, com intuito de verificar a influência do catalisador nos compostos estudados. Para coleta das emissões foi utilizada uma linha aquecida $\left(190{ }^{\circ} \mathrm{C}\right)$, para evitar condensação e perda de compostos provenientes do processo da combustão incompleta. A amostragem foi realizada em uma vazão de 6 l/min. As FIGURAS 5 e 6 apresentam o esquema de coleta das emissões em ensaios de veículos e motociclos, das emissões regulamentadas e não legisladas, com a técnica de FTIR.

Cumpre ressaltar que as análises pela técnica de FTIR foram executadas em um ensaio apenas, razão que impossibilita um tratamento estatístico dos resultados.

Na FIGURA 5 está demonstrada a inserção do FTIR para coleta das emissões brutas dos gases de escapamento no ponto denominado tailpipe, esquema utilizado para os veículos leves dos ciclos Otto e Diesel. 


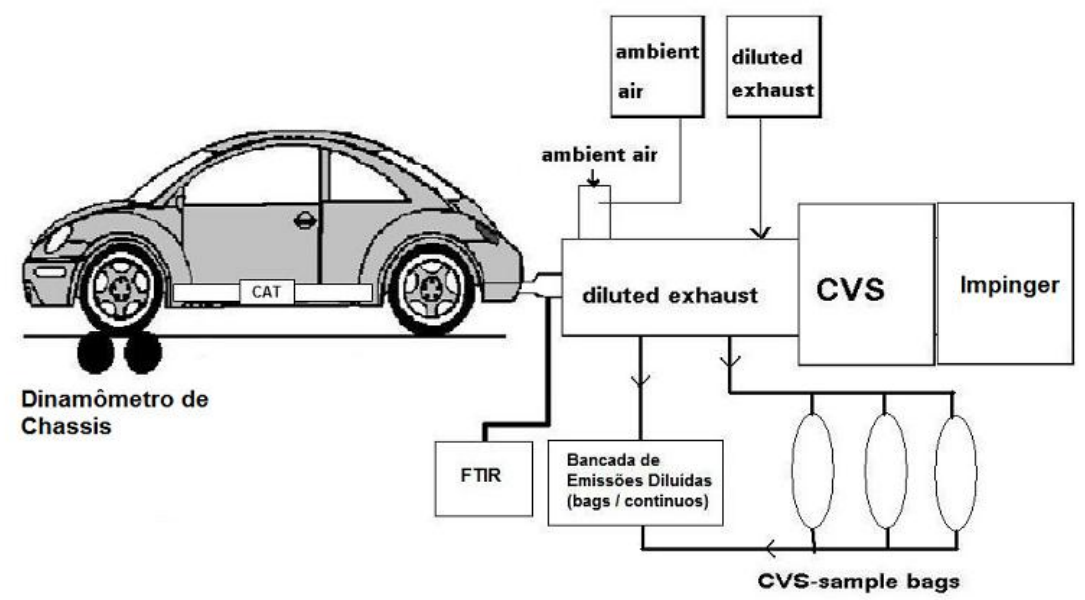

FIGURA 5: CONFIGURAÇÃO DE ENSAIO EM VEÍCULO OTTO E DIESEL COM USO DO FTIR. FONTE: PENTEADO et al. [21].

A FIGURA 6 apresenta a configuração típica de uma sala de ensaios em motociclos, com inserção do FTIR para coleta das emissões brutas dos compostos não legislados. Observam-se os pontos de coleta dos gases de escapamento antes do catalisador, amostragem efetuada na BK1, e após o catalisador (tailpipe) em todos os motociclos.

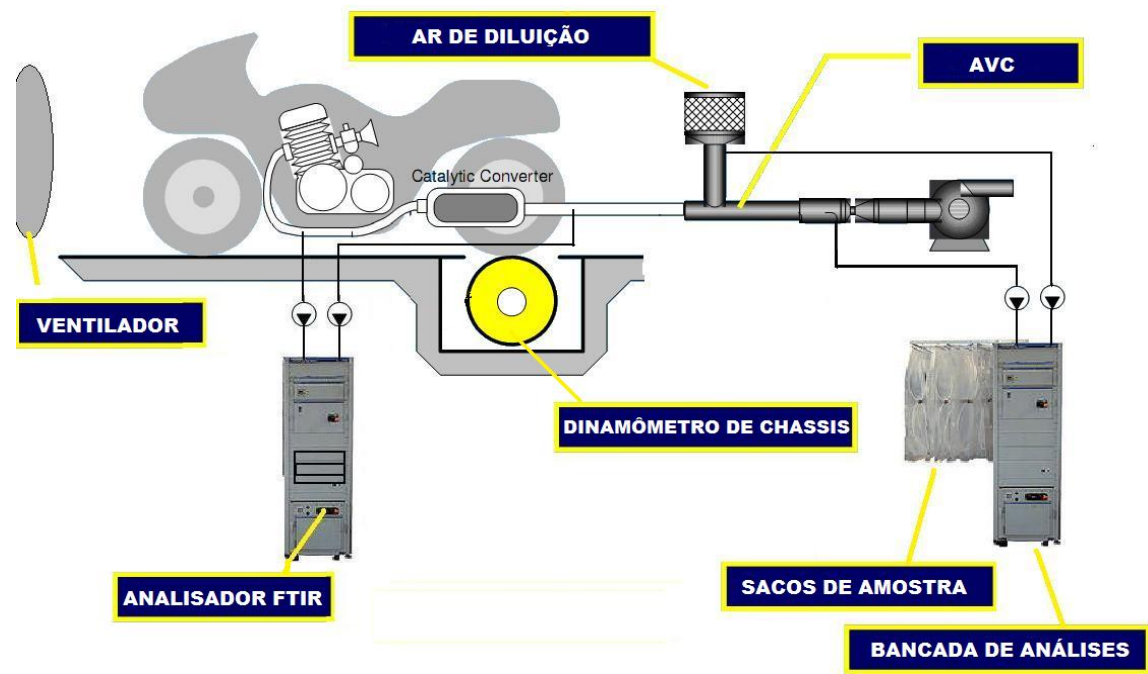

FIGURA 6: CONFIGURAÇÃO DE ENSAIO EM MOTOCICLO COM USO DO FTIR. FONTE: DAEMME [33].

\section{RESULTADOS}

\subsection{Motociclo BK1}

Os resultados (média aritmética e desvio padrão) das emissões legisladas para as gasolinas S800 e S50, são apresentados na forma de tabela, em que se observa uma redução nas emissões, com exceção do $\mathrm{CO}_{2}$ e do consumo de combustível, com uso da gasolina S50. Ainda é possível observar a diferença porcentual entre as emissões com uso da gasolina S50, comparada com a gasolina $\mathrm{S} 800$, e uma comparação com uso da análise de variância 
(ANOVA), demonstrando se houveram diferenças estatísticas significativas entre as médias comparadas. Para interpretação desses resultados, foram usadas as simbologias descritas na TABELA 5.

TABELA 5 SIMBOLOGIA PARA INTERPRETAÇÃO DA ANÁLISE DE VARIÂNCIA.

\begin{tabular}{cc}
\hline Simbologia & Interpretação \\
\hline$=$ & Médias estatisticamente iguais \\
\hline$\neq<$ & Médias diferentes, menor emissão com uso de S50 \\
\hline$\neq>$ & Médias diferentes, maior emissão com uso S50 \\
\hline
\end{tabular}

Na TABELA 6 estão apresentados os resultados. O regime de ensaio utilizado foi o ciclo WMTC. O motociclo em questão pertence à fase M3 do PROMOT.

TABELA 6 RESUMO DAS EMISSÕES DO MOTOCICLO BK1.

\begin{tabular}{|c|c|c|c|c|c|c|c|}
\hline \multicolumn{7}{|c|}{ Resumo Emissões Regulamentadas com gasolina S800 - g/km } & \multirow{2}{*}{$\begin{array}{l}\text { CONSUMO } \\
\mathrm{km} / 1\end{array}$} \\
\hline \multirow[b]{2}{*}{ Média } & THC & $\mathrm{CO}$ & $\mathrm{NO}_{\mathrm{X}}$ & $\mathrm{CO}_{2}$ & $\mathrm{CH}_{4}$ & NMHC & \\
\hline & 0.120 & 1.849 & 0.146 & 60.437 & 0.014 & 0.105 & 34.128 \\
\hline DP & 0.003 & 0.049 & 0.004 & 0.614 & 0.000 & 0.003 & 0.318 \\
\hline \multicolumn{7}{|c|}{ Resumo Emissões Regulamentadas com gasolina S50 - g/km } & CONSUMO \\
\hline \multirow[b]{2}{*}{ Média } & THC & $\mathrm{CO}$ & $\mathrm{NO}_{\mathrm{X}}$ & $\mathrm{CO}_{2}$ & $\mathrm{CH}_{4}$ & NMHC & $\mathrm{km} / \mathrm{l}$ \\
\hline & 0.103 & 1.722 & 0.108 & 62.133 & 0.013 & 0.090 & 33.370 \\
\hline DP & 0.002 & 0.073 & 0.003 & 0.163 & 0.001 & 0.002 & 0.104 \\
\hline Comparação & THC & $\mathrm{CO}$ & NOX & $\mathrm{CO} 2$ & $\mathrm{CH} 4$ & NMHC & AUTONOMIA \\
\hline DIF \% & $-16 \%$ & $-7 \%$ & $-35 \%$ & $3 \%$ & $-12 \%$ & $-17 \%$ & $-2 \%$ \\
\hline ANOVA & $\neq<$ & $\neq<$ & $\neq<$ & $\neq>$ & $\neq<$ & $\neq<<$ & $\neq<$ \\
\hline
\end{tabular}

A amostra BK1 foi instrumentada, em seu sistema de gases de exaustão, antes e após o catalisador, com intuito de verificar a influência do catalisador nos compostos estudados. As emissões não legisladas foram medidas e são apresentadas na TABELA 7, na qual se observa que a amônia é formada no catalisador, em ambas as gasolinas. Este fenômeno de geração de amônia no interior do catalisador está em estudo e alguns resultados e conclusões já foram publicados [17][18]. Observa-se que a emissão final de amônia, para o presente motociclo, apresentou uma tendência discreta de elevação com uso de gasolina S50.

TABELA 7 EMISSÕES DE AMÔNIA.

\begin{tabular}{c|c|c}
\hline Combustível & $\begin{array}{c}\text { Emissão } \mathrm{NH}_{3} \text { pré-cat } \\
(\mathrm{mg} / \mathrm{km})\end{array}$ & $\begin{array}{c}\text { Emissão } \mathrm{NH}_{3} \text { pós-cat } \\
(\mathrm{mg} / \mathrm{km})\end{array}$ \\
\hline $\mathrm{E} 22-\mathrm{S} 800$ & 0,412 & 74,557 \\
\hline $\mathrm{E} 22-\mathrm{S} 50$ & 0,225 & 77,852 \\
\hline
\end{tabular}

As FIGURAS 7 e 8 apresentam evolução das emissões de amônia antes e após o catalisador, em massa (mg), durante o ciclo de teste. 


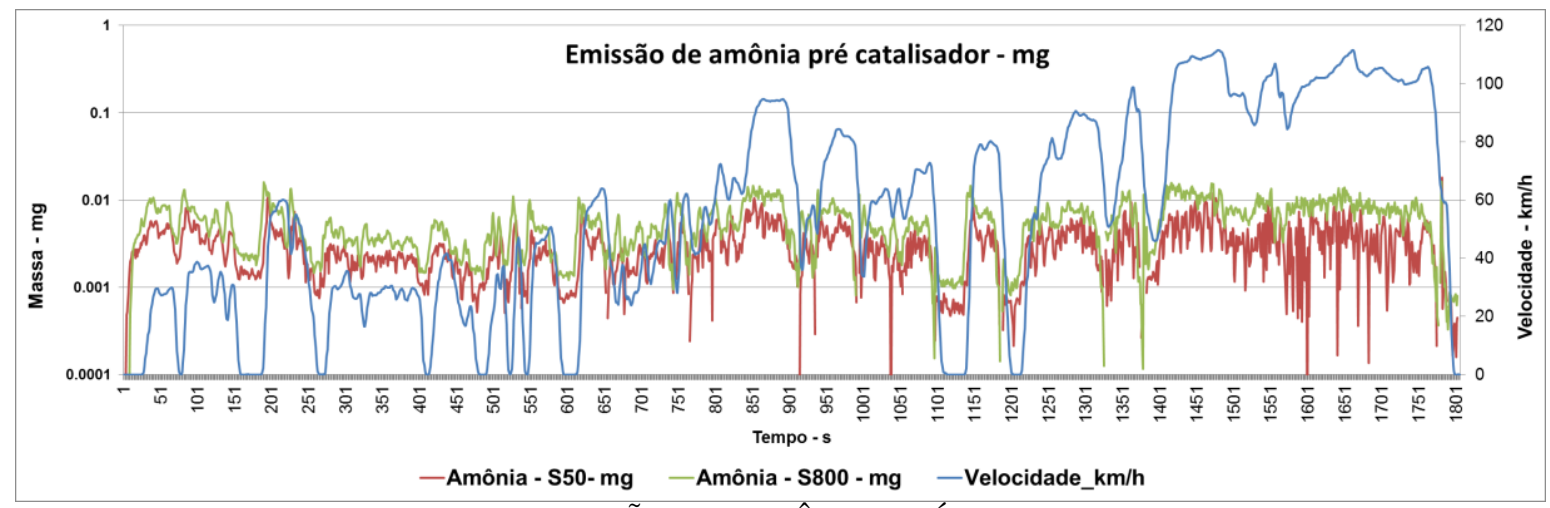

FIGURA 7: EMISSÃO DE AMÔNIA PRÉ CATALISADOR.

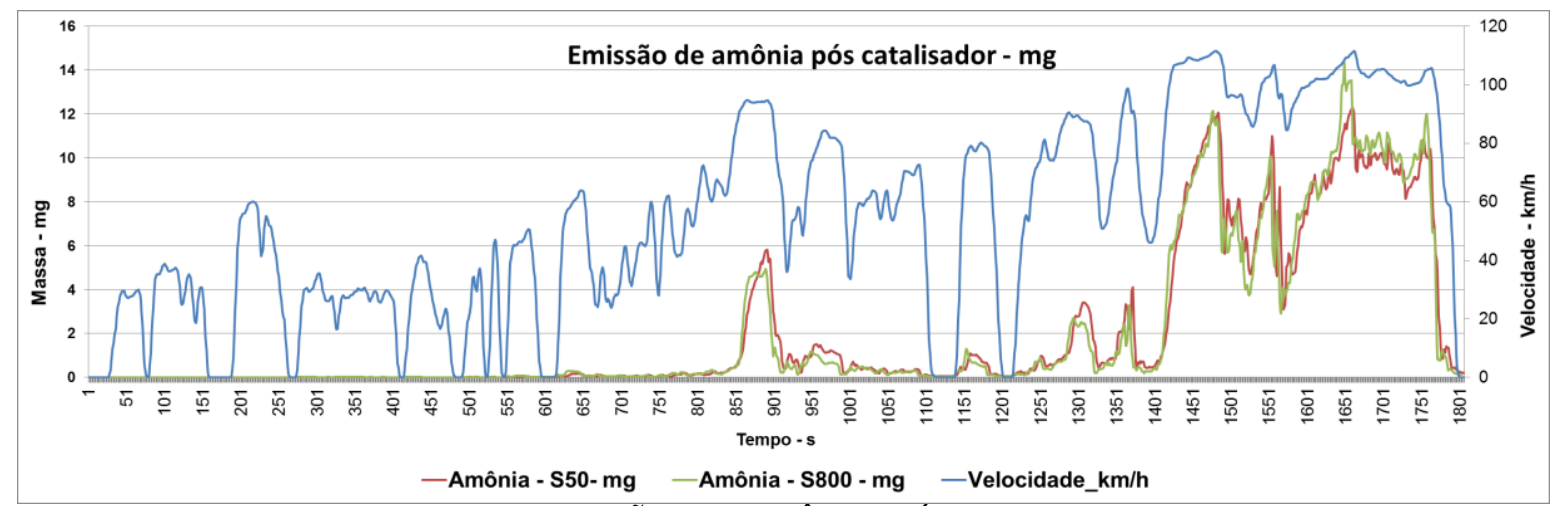

FIGURA 8: EMISSÃO DE AMÔNIA PÓS CATALISADOR.

A FIGURA 9 apresenta o perfil das temperaturas de operação do motociclo durante os ensaios de emissões. Foram coletadas as temperaturas antes do catalisador e ao final do tubo de exaustão dos gases (tailpipe).

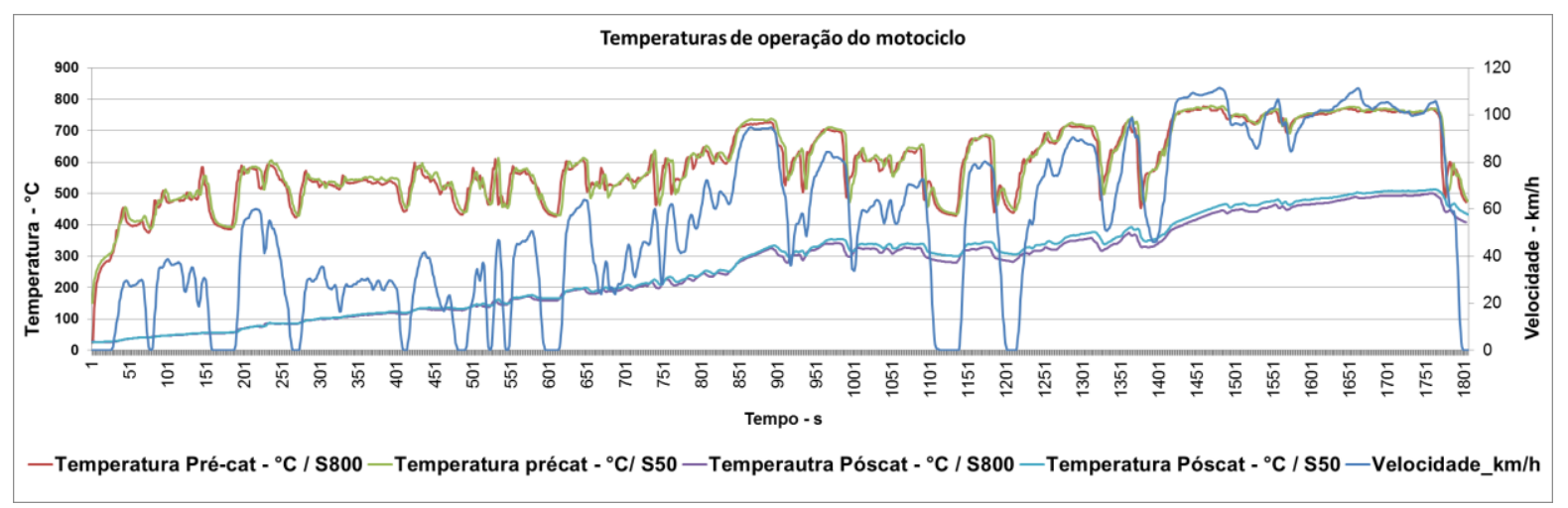

FIGURA 9: PERFIL DE TEMPERATURA NO CATALISADOR.

\subsection{Motociclo BK2}

Os resultados das emissões legisladas e de amônia, para as gasolinas S800 e S50, são apresentados na TABELA 8. Verifica-se, estatisticamente, uma redução nos valores de THC, $\mathrm{NO}_{\mathrm{x}}, \mathrm{CH}_{4}$ e NMHC quando é utilizada a gasolina S50. O teste foi realizado de acordo com a normativa EC 97/24, sendo executadas as fases urbana e extraurbana do ciclo de emissões. Observa-se que o motociclo pertence à fase M3 do PROMOT. 
TABELA 8 RESUMO DAS EMISSÕES DO MOTOCICLO BK2.

\begin{tabular}{|c|c|c|c|c|c|c|c|c|}
\hline \multicolumn{7}{|c|}{ Resumo Emissões Regulamentadas com gasolina S800 - g/km } & \multirow{2}{*}{$\begin{array}{c}\text { CONSUMO } \\
\mathrm{km} / \mathrm{l}\end{array}$} & \multirow{2}{*}{$\begin{array}{c}\mathrm{NH}_{3} \\
(\mathrm{mg} / \mathrm{km})\end{array}$} \\
\hline \multirow{2}{*}{ Média } & THC & $\mathrm{CO}$ & $\mathrm{NO}_{\mathrm{X}}$ & $\mathrm{CO}_{2}$ & $\mathrm{CH}_{4}$ & NMHC & & \\
\hline & 0,125 & 2,855 & 0,104 & 65,802 & 0,016 & 0,109 & 30,776 & 26,765 \\
\hline DP & 0,003 & 0,207 & 0,004 & 1,645 & 0,001 & 0,003 & 0,728 & - \\
\hline \multicolumn{7}{|c|}{ Resumo Emissões Regulamentadas com gasolina S50 - g/km } & CONSUMO & $\mathrm{NH}_{3}$ \\
\hline \multirow[b]{2}{*}{ Média } & THC & $\mathrm{CO}$ & $\mathrm{NO}_{\mathrm{X}}$ & $\mathrm{CO}_{2}$ & $\mathrm{CH}_{4}$ & NMHC & $\mathrm{km} / \mathrm{l}$ & $(\mathrm{mg} / \mathrm{km})$ \\
\hline & 0,115 & 2,693 & 0,089 & 67,288 & 0,014 & 0,102 & 30,278 & 30,104 \\
\hline DP & 0,004 & 0,117 & 0,002 & 2,603 & 0,001 & 0,004 & 1,076 & - \\
\hline Comparação & THC & $\mathrm{CO}$ & NOX & $\mathrm{CO} 2$ & $\mathrm{CH} 4$ & NMHC & AUTONOMIA & $\mathrm{NH}_{3}$ \\
\hline DIF \% & $-8 \%$ & $-6 \%$ & $-18 \%$ & $2 \%$ & $-19 \%$ & $-7 \%$ & $-2 \%$ & $11 \%$ \\
\hline ANOVA & $\neq<$ & $=$ & $\neq<$ & $=$ & $\neq<$ & $\neq<$ & $=$ & - \\
\hline
\end{tabular}

Quanto às emissões não legisladas, medidas pela técnica de FTIR após o catalisador, para a amostra BK2, observa-se um aumento de $11 \%$ na geração de amônia quando utilizada a gasolina S50.

A FIGURA 10 apresenta as emissões de amônia depois do catalisador, durante o ciclo de teste, com uso das gasolinas S50 e S800.

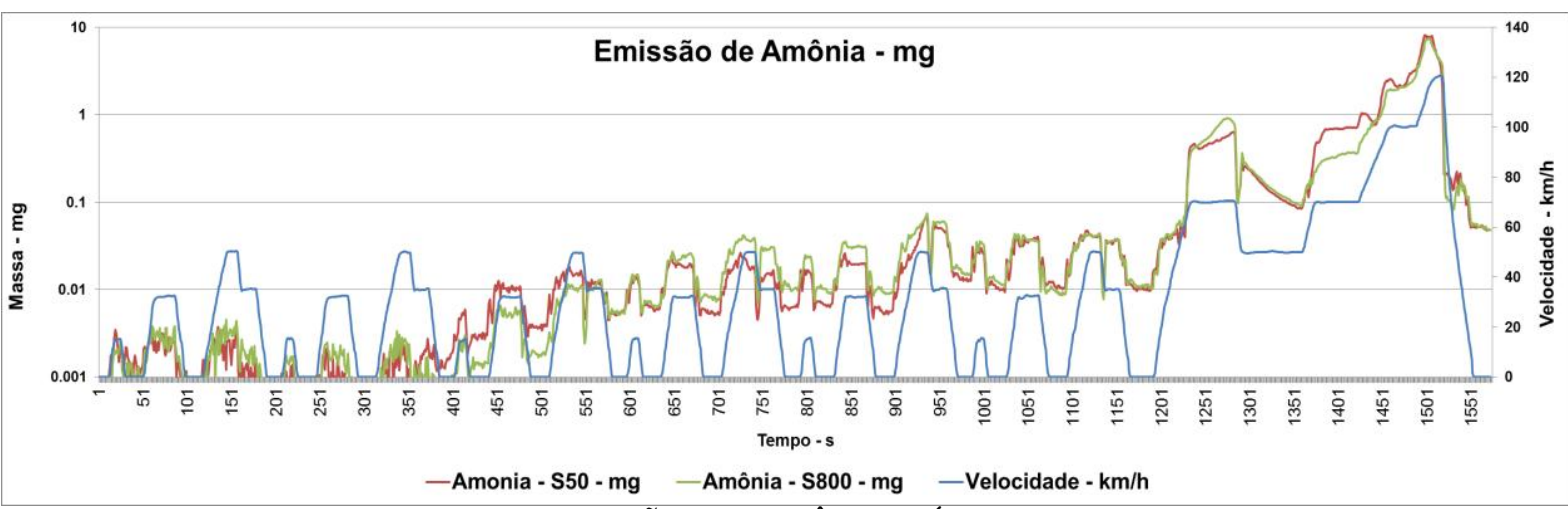

FIGURA 10: EMISSÃO DE AMÔNIA PÓS-CATALISADOR.

\subsection{Motociclo BK3}

Os resultados das emissões legisladas e não legisladas para as gasolinas S800 e S50, são apresentados na TABELA 9.

TABELA 9 RESUMO DAS EMISSÕES DO MOTOCICLO BK3.

\begin{tabular}{|c|c|c|c|c|c|c|c|c|}
\hline \multicolumn{7}{|c|}{ Resumo Emissões Regulamentadas com gasolina S800 - g/km } & \multirow{2}{*}{$\begin{array}{c}\text { CONSUMO } \\
\mathrm{km} / 1\end{array}$} & \multirow{2}{*}{$\begin{array}{c}\mathrm{NH}_{3} \\
(\mathrm{mg} / \mathrm{km})\end{array}$} \\
\hline \multirow{2}{*}{ Média } & THC & $\mathrm{CO}$ & $\mathrm{NO}_{\mathrm{X}}$ & $\mathrm{CO}_{2}$ & $\mathrm{CH}_{4}$ & NMHC & & \\
\hline & 0,395 & 3,867 & 0,149 & 44,287 & 0,018 & 0,377 & 42,239 & 0,165 \\
\hline DP & 0,046 & 0,528 & 0,016 & 2,371 & 0,002 & 0,044 & 2,417 & - \\
\hline \multicolumn{7}{|c|}{ Resumo Emissões Regulamentadas com gasolina S50 - g/km } & CONSUMO & $\mathrm{NH}_{3}$ \\
\hline \multirow[b]{2}{*}{ Média } & THC & $\mathrm{CO}$ & $\mathrm{NO}_{\mathrm{X}}$ & $\mathrm{CO}_{2}$ & $\mathrm{CH}_{4}$ & NMHC & $\mathrm{km} / \mathrm{l}$ & $(\mathrm{mg} / \mathrm{km})$ \\
\hline & 0,401 & 3,640 & 0,137 & 44,582 & 0,019 & 0,382 & 42,236 & 2,814 \\
\hline DP & 0,024 & 0,148 & 0,007 & 2,208 & 0,001 & 0,022 & 2,044 & - \\
\hline Comparação & $\mathrm{THC}$ & $\mathrm{CO}$ & NOX & $\mathrm{CO} 2$ & $\mathrm{CH} 4$ & NMHC & AUTONOMIA & $\mathrm{NH}_{3}$ \\
\hline DIF $\%$ & $2 \%$ & $-6 \%$ & $-9 \%$ & $1 \%$ & $4 \%$ & $1 \%$ & $-0,01 \%$ & $94 \%$ \\
\hline ANOVA & $=$ & $=$ & $=$ & $=$ & $=$ & $=$ & $=$ & - \\
\hline
\end{tabular}


Observa-se que não houve mudança significativa nas emissões legisladas para as gasolinas S50 e S800, sendo que as emissões de CO superam os limites de emissão de homologação $(2,0 \mathrm{~g} / \mathrm{km})$ da fase M3 a que pertence esse motociclo. Lembrando ainda que o motociclo em questão possuía no início dos testes $45.306 \mathrm{~km}$ rodados e que para essa classe de veículo automotor não havia uma regulamentação de durabilidade das emissões.

A FIGURA 11 apresenta a emissão de $\mathrm{NH}_{3}$ no decorrer do ciclo.

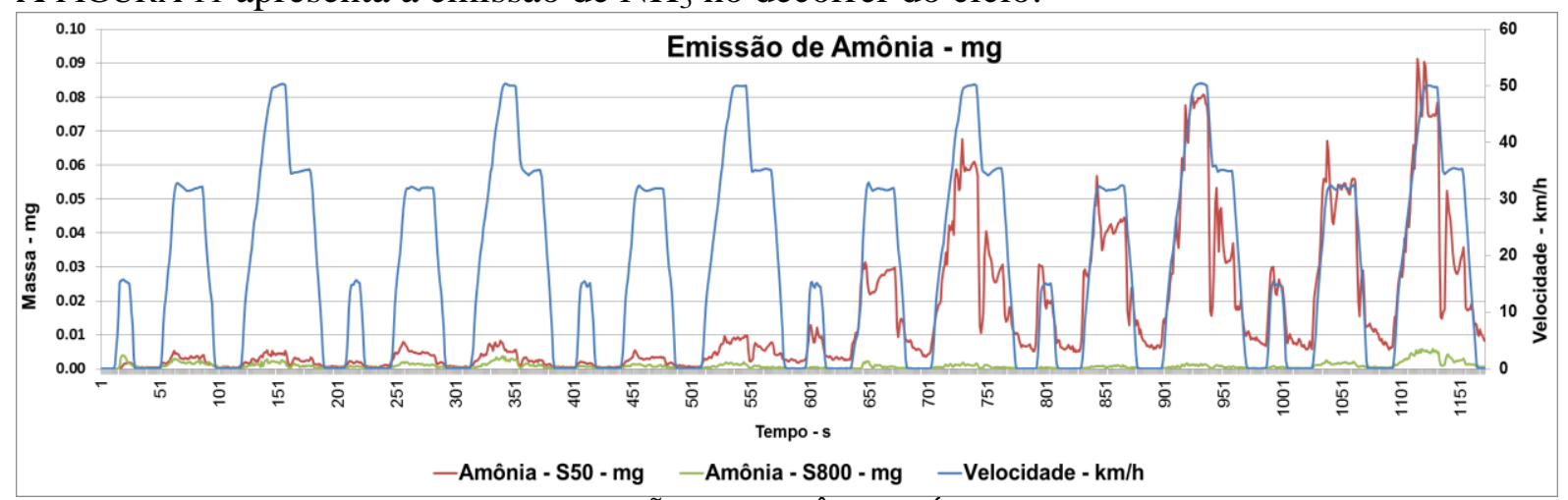

FIGURA 11: EMISSÃO DE AMÔNIA PÓS CATALISADOR.

3.4. Veículo leve de passageiros (Otto) - VP1

Os resultados das emissões legisladas e não legisladas para as gasolinas S800 e S50, são apresentadas na TABELA 10. No caso dos compostos legislados, ao passar de S800 para S50, houve uma redução das emissões de $\mathrm{THC}, \mathrm{NO}_{\mathrm{x}}$ e $\mathrm{CH}_{4}$. No caso da amônia, ocorreu um aumento da ordem de 20\%. Para o veículo observam-se emissões muito acima dos limites preconizados para sua fase de homologação (fase L4). Como o odômetro do veículo indicava mais de $125.000 \mathrm{~km}$ rodados, conclui-se, que o catalisador, que é desenvolvido para uma durabilidade mínima das emissões de $80.000 \mathrm{~km}$, encontra-se degradado.

TABELA 10 RESUMO DAS EMISSÕES DO VEÍCULO LEVE PASSAGEIROS - VP1.

\begin{tabular}{|c|c|c|c|c|c|c|c|c|}
\hline \multicolumn{7}{|c|}{ Resumo Emissões Regulamentadas com gasolina S800 - g/km } & \multirow{2}{*}{$\begin{array}{c}\text { CONSUMO } \\
\mathrm{km} / \mathrm{l}\end{array}$} & \multirow{2}{*}{$\begin{array}{c}\mathrm{NH}_{3} \\
(\mathrm{mg} / \mathrm{km})\end{array}$} \\
\hline \multirow{2}{*}{ Média } & THC & $\mathrm{CO}$ & $\mathrm{NO}_{\mathrm{X}}$ & $\mathrm{CO}_{2}$ & $\mathrm{CH}_{4}$ & NMHC & & \\
\hline & 0,476 & 2,958 & 1,065 & 158,877 & 0,036 & 0,440 & 13,176 & 4,643 \\
\hline DP & 0,017 & 0,174 & 0,032 & 0,922 & 0,002 & 0,015 & 0,052 & - \\
\hline \multicolumn{7}{|c|}{ Resumo Emissões Regulamentadas com gasolina S50 - g/km } & CONSUMO & $\mathrm{NH}_{3}$ \\
\hline \multirow[b]{2}{*}{ Média } & THC & $\mathrm{CO}$ & $\mathrm{NO}_{\mathrm{X}}$ & $\mathrm{CO}_{2}$ & $\mathrm{CH}_{4}$ & NMHC & $\mathrm{km} / \mathrm{l}$ & $(\mathrm{mg} / \mathrm{km})$ \\
\hline & 0,433 & 2,868 & 0,942 & 155,838 & 0,031 & 0,403 & 13,451 & 5,822 \\
\hline DP & 0,011 & 0,149 & 0,036 & 3,606 & 0,001 & 0,011 & 0,318 & - \\
\hline Comparação & THC & $\mathrm{CO}$ & NOX & $\mathrm{CO} 2$ & $\mathrm{CH} 4$ & NMHC & AUTONOMIA & $\mathrm{NH}_{3}$ \\
\hline DIF \% & $-10 \%$ & $-3 \%$ & $-13 \%$ & $-2 \%$ & $-16 \%$ & $-9 \%$ & $2 \%$ & $20 \%$ \\
\hline ANOVA & $\neq<$ & $=$ & $\neq<$ & $=$ & $\neq<<$ & $\neq<$ & $=$ & - \\
\hline
\end{tabular}

Como observado nos motociclos, a redução do teor de enxofre apresentou tendências de aumento na emissão de $\mathrm{NH}_{3}$.

A FIGURA 12 demonstra as emissões de $\mathrm{NH}_{3}$ nos gases de escapamento após o catalisador. Observa-se que na primeira fase houve uma maior emissão de $\mathrm{NH}_{3}$ para o combustível S800. 


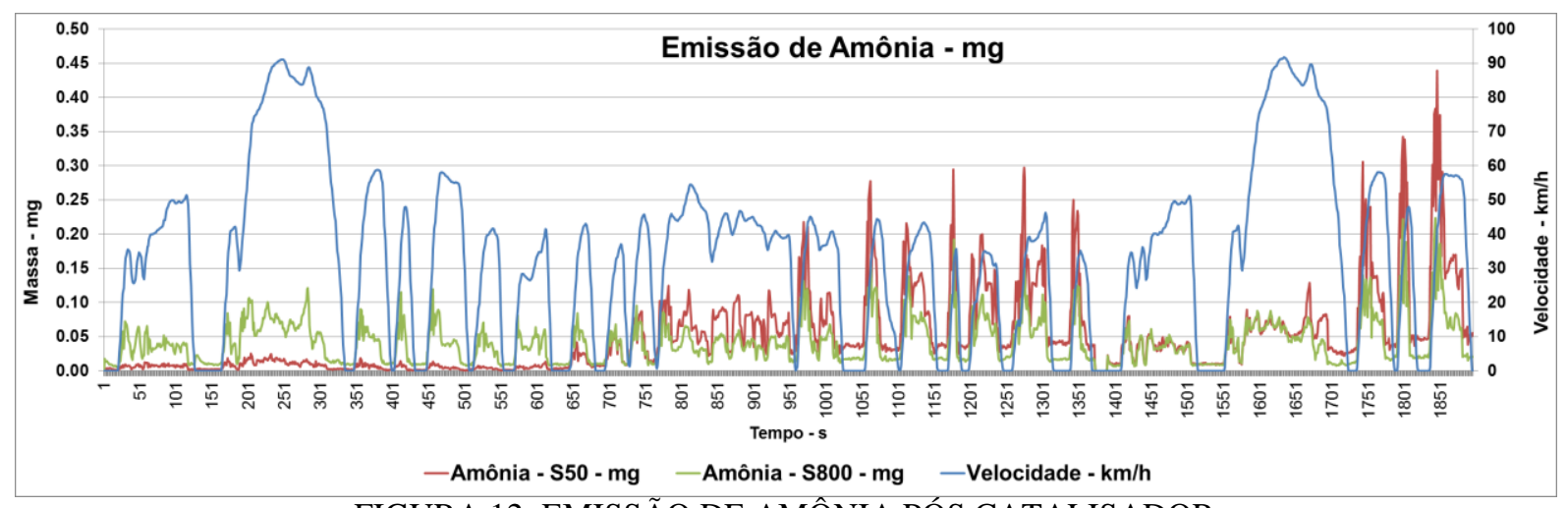

FIGURA 12: EMISSÃO DE AMÔNIA PÓS CATALISADOR.

\subsection{Considerações sobre os resultados nos veículos do ciclo Otto}

Cumpre ressaltar que as comparações possuem limitações, pois as amostras são de anos de fabricação e quilometragens diferentes, com motores e ciclos de rodagem também diferentes. Assim, a moto BK3 tem motor de 150 cc enquanto a BK1 e a BK2 têm motor de 300 cc. Já, a moto BK1 foi avaliada segundo o ciclo WMTC, que é um ciclo mais "agressivo" que o Euro (utilizado no caso das outras duas motos, BK2 e BK3) desenvolvendo velocidades mais altas que propiciam uma maior temperatura nos gases de exaustão. No entanto, apesar das limitações citadas, algumas tendências podem ser observadas.

Nota-se que, com o aumento da quilometragem dos veículos em teste, há uma tendência de aumento na maioria das emissões legisladas. Esse aumento das emissões com o uso veículo, normalmente está associado ao envelhecimento térmico do catalisador. Nesses casos, esperase um aumento da sinterização dos componentes do catalisador, com consequente desativação parcial do mesmo.

Com relação a uma possível desativação química pelo teor de enxofre da gasolina, nota-se que a mudança de S800 para S50, segundo metodologia dos ensaios realizados, levou a uma queda nas emissões (FIGURA 13), conforme esperado, tendo em conta que o enxofre interage fortemente com alguns componentes ativos do catalisador como os metais nobres, impedindo a interação necessária desses metais com os contaminantes. Assim, uma queda no teor de enxofre favorece a conversão dos poluentes. Nota-se ainda que com o aumento da quilometragem, há a tendência de diminuição do impacto do teor de enxofre nas emissões que, por outro lado, aumentam. Aparentemente, com o tempo de uso a desativação térmica vai ganhando importância em detrimento da desativação química.

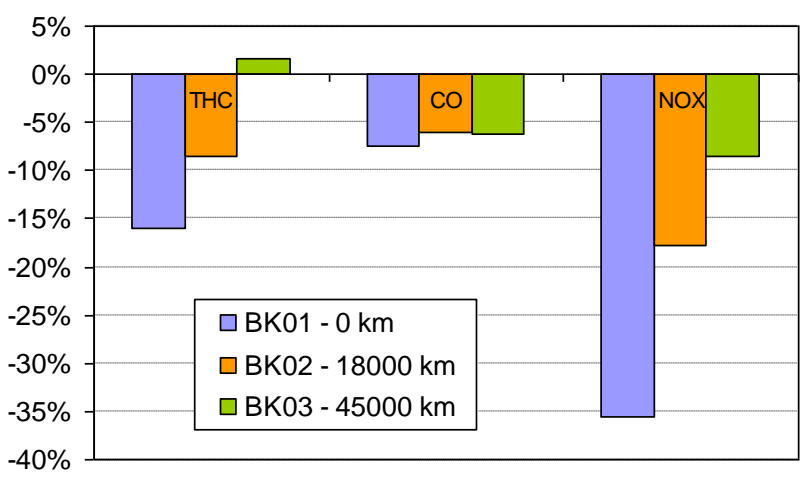

FIGURA 13: Percentual de redução nas emissões de THC, CO e NOx quando se reduz o teor de enxofre de 800 para 50 ppm, para as três motocicletas em estudo. 
Quanto às emissões não regulamentadas de amônia apresenta-se uma análise relativa à motocicleta BK01, instrumentada, que permitiu o acompanhamento das emissões antes a após o catalisador, bem como a evolução da temperatura ao longo do ciclo. Considera-se as mesmas limitações comentadas no item anterior, além do fato de a amostragem com o FTIR ter sido realizada apenas uma vez com cada combustível.

Numa análise das emissões pré-catalisador, verifica-se que a quantidade de amônia formada é relativamente baixa antes do catalisador e diminui quando se usa gasolina S50 (TABELA 6).

Uma análise pós-catalisador mostra, no entanto, um cenário muito mais crítico. As emissões de amônia aumentaram em, no mínimo, 180 vezes. Uma possível explicação para esse comportamento está associada a alguns fatores como: a gasolina utilizada no Brasil, que tem um teor de etanol médio entre 20 e $25 \%$; às condições reacionais no interior do catalisador, que oscila entre ambiente oxidante e ambiente redutor em ampla faixa de temperatura e ao próprio catalisador que apresenta componentes ativos, por exemplo, metais nobres, que promovem várias reações. Normalmente, a formação de amônia ocorre em condições ricas, através de uma reação entre os $\mathrm{NO}_{\mathrm{x}}$ e o $\mathrm{H}_{2}$, hidrogênio este que deve estar sendo formado através da reação de deslocamento de monóxido de carbono com vapor d'água (water gasshift reaction - WGS) ou reações de reforma que ocorrem no catalisador, inclusive a partir do etanol não convertido.

Comparando-se as emissões de amônia (pós-catalisador) nas três motocicletas em análise, observa-se que existe uma queda muito grande na formação de $\mathrm{NH}_{3}$ com o aumento de quilometragem, provavelmente devido ao envelhecimento do catalisador, já que a moto com menor rodagem é a que emite mais. Assim, um aumento do desgaste do catalisador com o uso, provavelmente ligado à queda na área específica do catalisador, diminui consideravelmente as emissões de amônia.

A questão do enxofre nessas emissões mostra certa tendência de aumento na formação de amônia quando se diminui o teor de enxofre da gasolina. Esses resultados concordam com observado nas pesquisas de Centeno et al. [7].

Estudos mais detalhados serão necessários para um completo entendimento da variação na formação de $\mathrm{NH}_{3}$ com o teor de enxofre, bem como a questão do etanol nesse meio.

Uma avaliação dos perfis de concentração de amônia emitida ao longo do tempo para a motocicleta BK1 (FIGURA 8) mostram a importância da temperatura nas emissões. Observase um grande aumento nas emissões quando a temperatura ultrapassa $750^{\circ} \mathrm{C}$ (FIGURA 9), provavelmente por, nessas condições, se favorecer termodinamicamente a formação de hidrogênio via reações de reforma a vapor de álcoois e hidrocarbonetos [34]. Nessa região de altas temperaturas, não se observa uma relação entre o teor de enxofre e a quantidade de amônia emitida após o catalisador.

\subsection{Veículo Comercial leve do ciclo Diesel - CL1}

Os resultados das emissões legisladas e não legisladas para os óleos diesel S500 e S10, são mostrados na TABELA 11. No caso dos compostos legislados, com a mudança de S500 para S10, houve uma redução das emissões de THC, CO, NOx, NMHC e material particulado. No caso da amônia, os resultados não apresentaram diferenças. O veículo em questão pertence à fase L3 do PROCONVE. 
TABELA 11 RESUMO DAS EMISSÕES DO VEÍCULO LEVE PASSAGEIROS CL1.

\begin{tabular}{|c|c|c|c|c|c|c|c|c|}
\hline \multicolumn{7}{|c|}{ Resumo Emissões Regulamentadas com gasolina S500 - g/km } & \multirow{2}{*}{$\begin{array}{c}\text { CONSUMO } \\
\mathrm{km} / 1\end{array}$} & \multirow{2}{*}{$\begin{array}{c}\mathrm{NH}_{3} \\
(\mathrm{mg} / \mathrm{km})\end{array}$} \\
\hline \multirow{2}{*}{ Média } & THC & $\mathrm{CO}$ & $\mathrm{NO}_{\mathrm{X}}$ & $\mathrm{CO}_{2}$ & NMHC & PM & & \\
\hline & 0,388 & 0,872 & 2,132 & 281,704 & 0,381 & 0,077 & 9,580 & 6,010 \\
\hline DP & 0,012 & 0,108 & 0,029 & 7,644 & 0,011 & 0,017 & 0,254 & - \\
\hline \multicolumn{7}{|c|}{ Resumo Emissões Regulamentadas com gasolina $\mathrm{S} 10-\mathrm{g} / \mathrm{km}$} & CONSUMO & $\mathrm{NH}_{3}$ \\
\hline \multirow[b]{2}{*}{ Média } & THC & $\mathrm{CO}$ & $\mathrm{NO}_{\mathrm{X}}$ & $\mathrm{CO}_{2}$ & NMHC & PM & $\mathrm{km} / \mathrm{l}$ & $(\mathrm{mg} / \mathrm{km})$ \\
\hline & 0,206 & 0,388 & 1,885 & 285,207 & 0,201 & 0,044 & 9,388 & 5,713 \\
\hline DP & 0,039 & 0,081 & 0,168 & 9,566 & 0,038 & 0,007 & 0,313 & - \\
\hline Comparação & THC & $\mathrm{CO}$ & $\mathrm{NO}_{X}$ & $\mathrm{CO}_{2}$ & NMHC & PM & AUTONOMIA & $\mathrm{NH}_{3}$ \\
\hline DIF \% & $-88 \%$ & $-124 \%$ & $-13 \%$ & $1 \%$ & $-90 \%$ & $-73 \%$ & $-2 \%$ & $5 \%$ \\
\hline ANOVA & $\neq<$ & $\neq<$ & $\neq<$ & $=$ & $\neq<$ & $\neq<$ & $=$ & - \\
\hline
\end{tabular}

A FIGURA 14 apresenta a emissão de amônia durante o ciclo de emissões em dinamômetro.

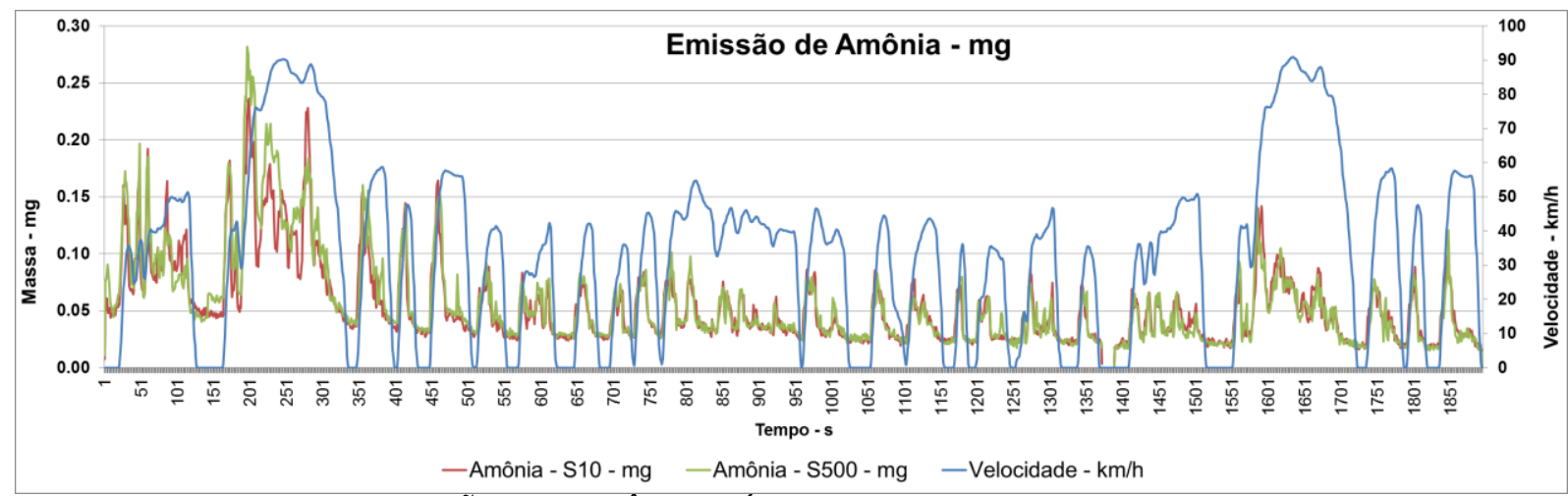

FIGURA 14: EMISSÃO DE AMÔNIA PÓS CATALISADOR COM DIESEL S10 E S500

\subsection{Veículo Comercial leve do ciclo Diesel - CL2}

Os resultados das emissões legisladas e não legisladas para o diesel S500 e S10, são mostrados na TABELA 12. No caso dos compostos legislados, ao passar de S500 para S10, houve uma redução das emissões de THC, $\mathrm{CO}, \mathrm{NO}_{\mathrm{x}}, \mathrm{NMHC}$ e material particulado. No caso da amônia houve uma redução com uso do diesel S10. Os limites de homologação da fase em que o veículo está enquadrado (L6), para as emissões de $\mathrm{NO}_{\mathrm{x}}$ e material particulado, foram ultrapassados quando se utilizou o diesel S500.

TABELA 12 RESUMO DAS EMISSÕES DO VEÍCULO LEVE PASSAGEIROS CL2.

\begin{tabular}{|c|c|c|c|c|c|c|c|c|}
\hline \multicolumn{7}{|c|}{ Resumo Emissões Regulamentadas com gasolina S500 - g/km } & \multirow{2}{*}{$\begin{array}{c}\text { CONSUMO } \\
\mathrm{km} / \mathrm{l}\end{array}$} & \multirow{2}{*}{$\begin{array}{c}\mathrm{NH}_{3} \\
(\mathrm{mg} / \mathrm{km})\end{array}$} \\
\hline \multirow{2}{*}{ Média } & THC & $\mathrm{CO}$ & $\mathrm{NO}_{\mathrm{X}}$ & $\mathrm{CO}_{2}$ & NMHC & PM & & \\
\hline & 0,065 & 0,152 & 0,396 & 259,430 & 0,044 & 0,061 & 10,476 & 1,967 \\
\hline DP & 0,011 & 0,031 & 0,011 & 2,711 & 0,011 & 0,011 & 0,106 & - \\
\hline \multicolumn{7}{|c|}{ Resumo Emissões Regulamentadas com gasolina $\mathrm{S} 10-\mathrm{g} / \mathrm{km}$} & CONSUMO & $\mathrm{NH}_{3}$ \\
\hline \multirow[b]{2}{*}{ Média } & THC & $\mathrm{CO}$ & $\mathrm{NO}_{\mathrm{X}}$ & $\mathrm{CO}_{2}$ & $\mathrm{NMHC}$ & PM & $\mathrm{km} / 1$ & $(\mathrm{mg} / \mathrm{km})$ \\
\hline & 0,040 & 0,083 & 0,319 & 258,230 & 0,024 & 0,030 & 10,398 & 1,190 \\
\hline DP & 0,005 & 0,005 & 0,003 & 2,786 & 0,004 & 0,003 & 0,113 & - \\
\hline Comparação & THC & $\mathrm{CO}$ & $\mathrm{NO}_{X}$ & $\mathrm{CO}_{2}$ & NMHC & PM & AUTONOMIA & $\mathrm{NH}_{3}$ \\
\hline DIF \% & $-62 \%$ & $-82 \%$ & $-24 \%$ & $0 \%$ & $-82 \%$ & $-103 \%$ & $-1 \%$ & $65 \%$ \\
\hline ANOVA & $\neq<$ & $\neq<$ & $\neq<$ & $=$ & $\neq<$ & $\neq<$ & $=$ & - \\
\hline
\end{tabular}

Na FIGURA 15 são apresentadas as emissões de amônia para o veículo CL2 durante o ensaios de emissões. 


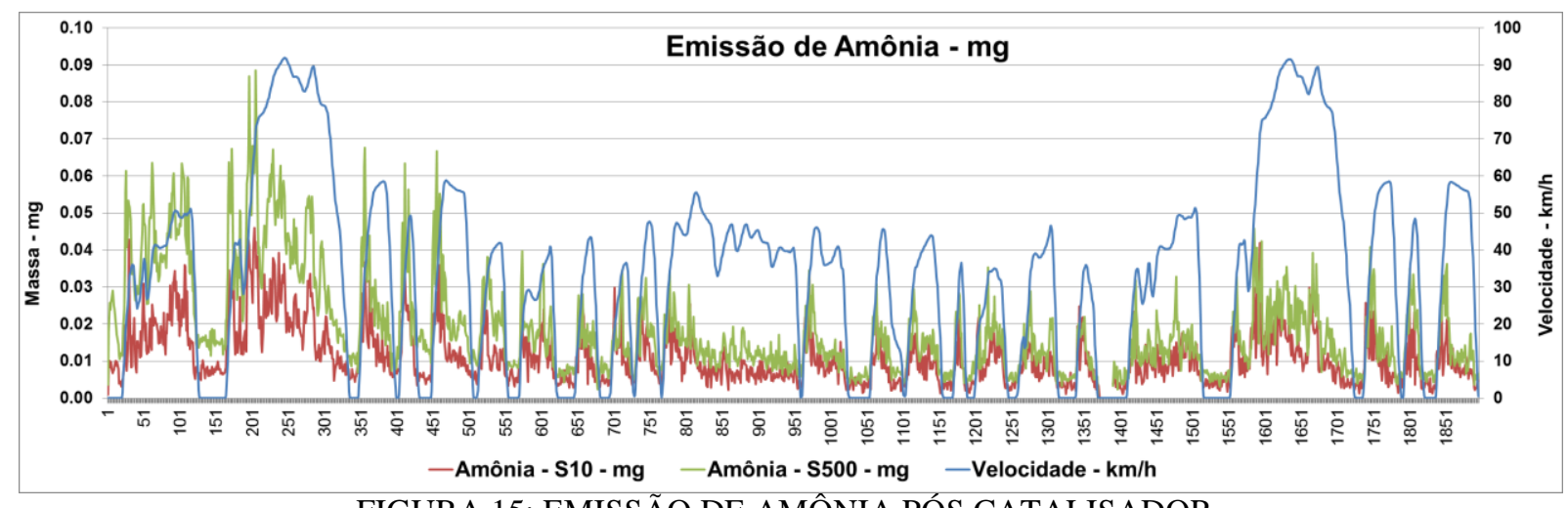

FIGURA 15: EMISSÃO DE AMÔNIA PÓS CATALISADOR.

\subsection{Considerações sobre os resultados nos veículos do ciclo Diesel}

Redução nas emissões legisladas, com uso de S10, com destaque ao material particulado que teve reduções superiores a 70\% nas duas amostras, com uso do combustível de baixo teor de enxofre.

Referente às emissões de amônia, observou-se que a redução do teor de enxofre proporcionou uma diminuição dessas emissões, principalmente no veículo CL2. Observamos que os veículos do ciclo Diesel não são equipados com catalisadores de três vias, que segundo a literatura são responsáveis pela formação de amônia, e as informações sobre esse tipo de emissão são escassas para os veículos dessa natureza.

\section{CONCLUSÃO}

Dentro das limitações destacadas, este trabalho mostrou que uma queda no teor de enxofre dos combustíveis utilizados no experimento melhora significativamente as emissões dos

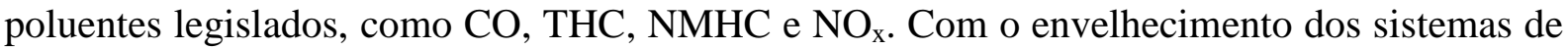
pós tratamento de veículos Otto, observa-se um aumento na maioria das emissões legisladas bem como a tendência de diminuição do impacto do teor de enxofre nas emissões, provavelmente associados ao degradação térmica dos catalisadores.

Com relação a emissões não legisladas, a quantidade de amônia formada é relativamente baixa antes do catalisador e diminui quando se usa gasolina S50 (Tabela 5). Contudo, após o catalisador a emissão de amônia aumenta. Esse fato pode estar associado à presença de etanol não convertido, que pode sofrer reação de reforma e gerar hidrogênio, favorecendo a formação de $\mathrm{NH}_{3}$. $\mathrm{O}$ óxido nitroso pode estar sendo formado sobre o óxido misto contendo Ce.

As emissões de amônia parecem depender do nível de envelhecimento sofrido pelo catalisador. Com o aumento da quilometragem observou-se uma diminuição drástica das emissões de $\mathrm{NH}_{3}$. A temperatura tem um impacto importante na emissão desse poluente que aumenta nos momentos de maior temperatura. 
O impacto do enxofre nessas emissões foi também observado e mostrou que a queda no teor de enxofre tende a promover a formação de amônia. Esse resultado deve ser reavaliados em estudos posteriores mais detalhados e completos.

Apesar da tendência de elevação dos níveis de emissão da amônia com menor teor de enxofre no combustível, observou-se um ganho nas emissões regulamentadas, com saldo benéfico para o meio ambiente.

\section{AGRADECIMENTOS}

Os autores agradecem ao Ministério da Ciência e Tecnologia e ao CNPq (Conselho Nacional de Desenvolvimento Científico e Tecnológico) pelo incentivo recebido com a aplicação da Lei 8010/90. Agradecem também à equipe do Laboratório de Emissões Veiculares do Lactec, onde foram realizados os testes de emissões, à PETROBRAS, IBAMA, ANP e ao Programa de Pós-Graduação em Engenharia de Recursos Hídricos e Ambiental (PPGERHA) da UFPR.

\section{REFERÊNCIAS}

[1] RODRIGUES, M. C.; GUARIEIRO, L. L. N.; CARDOSO, M. P.; CARVALHO, L. S.; ROCHA, G. O.; ANDRADE, J. B. Acetaldehyde and formaldehyde concentrations from sites impacted by heavy-duty diesel vehicles and their correlation with the fuel composition: Diesel and diesel/biodiesel blends. Fuel. No. 92, p. 258-263, 2012.

[2] NING, Z.; WUBULIHAIREN, M.; YANG, F. PM, $\mathrm{NO}_{\mathrm{x}}$ and butane emissions from on-road vehicle fleets in Hong Kong and their implications on emission control policy. Atmospheric Environment. No. 61, p. 265-274, 2012.

[3] BRASIL. MINISTÉRIO DO MEIO AMBIENTE, Resolução CONAMA no ${ }^{18}$. Dispõe sobre a criação do Programa de Controle de Poluição do Ar por veículos Automotores - PROCONVE, 1986. Publicada no DOU, de 17 de junho de 1986, Seção 1, páginas 8792-8795.

[4] BRASIL. MINISTÉRIO DO MEIO AMBIENTE, Resolução CONAMA nº 297. Estabelecimento dos limites para emissões de gases poluentes por ciclomotores, motociclos e veículos similares novos, 2002. Publicada no DOU no. 51, de 15 de março de 2002, Seção 1, páginas 86-88.

[5] KARAVALAKIS, G.; POULOPOULOS, S.; ZERVAS, E. Impact of diesel fuels on the emissions of non-regulated pollutants. Fuel. No. 102, 84-91, 2012.

[6] CENTENO, I. M.; HERNÁNDEZ, A. M.; FUENTES, G. A. Effect of low-sulfur fuels upon $\mathrm{NH}_{3}$ and $\mathrm{N}_{2} \mathrm{O}$ emission during operation of commercial three-way catalytic converters. Topics in Catalysis. Volumes 42-43, 381-385, 2007.

[7] CENTENO, I. M.; CASTILLO, S.; FUENTES, G. A. Enhanced emissions of NH3, N2O and H2 from a Pd-only TWC and supported Pd model catalysts: Light-off and sulfur level studies. Applied Catalysis B: Environmental. No. 119-120, p. 234-240, 2012.

[8] KEAN, A. J.; LITTLEJOHN, D.; BAN-WEISS, G. A.; HARLEY, R. A.; KIRCHSTETTER, T. W.; LUNDEN, M. M. Trends in on-road vehicle emissions of ammonia. Atmospheric Environment. No. 43, p. 1565-1570, 2009.

[9] DURBIN, T. D.; WILSON, R. D.; NORBECK, J. M.; MILLER, J. W.; HUAI, T.; RHEE, S. H. Estimates of the emission rates of ammonia from light-duty vehicles using standard chassis dynamometer test cycles. Atmospheric Environment. No. 36, 1475-1482, 2002.

[10] HUAI, T.; DURBIN, T. D.; MILLER, J. W.; PISANO, J. T.; SAUER, G. S.; RHEE, S. H.; NORBECK, J. M. Investigation of NH3 Emissions from New Technology Vehicles as a Function of Vehicle Operating Conditions. Environ. Sci. Technol. No. 37, p. 4841-4847, 2003. 
[11] HEEB, N. V.; SAXER, C. J.; FORSS, A. M.; BRÜHLMANN, S. Trends of NO-, NO2-, and NH3-emissions from gasoline-fueled Euro-3- to Euro-4-passenger cars. Atmospheric Environment. No. 42, 2543-2554, 2008.

[12] KEAN, A. J.; LITTLEJOHN, D.; BAN-WEISS, G. A.; HARLEY, R. A.; KIRCHSTETTER, T. W.; LUNDEN, M. M. Trends in on-road vehicle emissions of ammonia. Atmospheric Environment. No. 43, p. 1565-1570, 2009.

[13] Phan, N. T.; Kima, K. H.; Shon, Z. H.; Jeon, E. C.; Jung, K.; Kimc, N. J. Analysis of ammonia variation in the urban atmosphere. Atmospheric Environment. No. 65, p. 177-185, 2013.

[14] LIVINGSTON, C.; RIEGER, P.; WINER, A. Ammonia emissions from a representative inuse fleet of light and medium-duty vehicles in the California South Coast Air Basin. Atmospheric Environment. No. 43, p.3326-3333, 2009

[15] FELIX, E. P.; CARDOSO, A. A. Amônia (NH3) atmosférica: Fontes, transformação, sorvedouros e métodos de análise. Química Nova. Vol. 27, No. 1, 123-130, 2004.

[16] DURBIN, T. D. D.; PISANO, J. T.; YOUNGLOVE, T.; SAUER, C. G.; RHEE, S. H.; HUAI, T.; MILLER, J. W.; MACKAY, G. I.; HOCHHAUSER, A. M.; INGHAM, M. C.; GORSE, R. A.; BEARD, L. K.; DICICCO, D.; THOMPSON, N.; STRADLING, R. J.; RUTHERFORD, J. A.; UIHLEIN, J. P. The effect of fuel sulfur on NH3 and other emissions from 2000-2001 model year vehicles. Atmospheric Environment. No. 38, p. 2699-2708, 2004.

[17] PENTEADO, R. A.; DAEMME, L. C.; MELO, T. C. C. An experimental investigation on regulated and unregulated emissions from four 4-stroke gasoline-powered motorcycle. In: SAE 2012 World Congress. 2012-01-1098, Detroit, 2012.

[18] PENTEADO, R. A.; DAEMME, L. C.; JÜRGEN, K.; ZOTIN, F. A Study on Regulated and Unregulated Emissions from a Set of Five Gasoline and Ethanol Fueled Motorcycles. In: SAEChina; FISITA (Eds.). (Org.). Proceedings of the FISITA 2012 World Automotive Congress, 1ed. Springer Berlin Heidelberg, 2013, v. 189, p. 687-698.

[19] BRASIL. MINISTÉRIO DO MEIO AMBIENTE. Instrução Normativa IBAMA n ${ }^{\circ} 6$, de 8 de junho de 2010. Publicada no DOU de 09.06.2010.

[20] ABNT. NBR 6601: Determinação de hidrocarbonetos, monóxido de carbono, óxidos de nitrogênio, dióxido de carbono e material particulado no gás de escapamento, 2012.

[21] DAEMME, L. C.; PENTEADO, R. A.; PEREIRA, F.; FERREIRA, R. S. Emissões legisladas e não-legisladas geradas em veículo automotor leve do ciclo Diesel. In: SIMPÓSIO INTERNACIONAL DE ENGENHARIA AUTOMOTIVA - SIMEA, XIX, 2011, São Paulo. Trabalhos apresentados... São Paulo, 2011.

[22] SILVA, A. V. F.; CARVALHO, F. L.; BASSI, G. V. Métodos alternativos de coleta de aldeídos nas emissões veiculares visando redução do consumo e descarte de acetonitrila. In: SIMPÓSIO INTERNACIONAL DE ENGENHARIA AUTOMOTIVA - SIMEA, XVIII, 2011, São Paulo. Trabalhos apresentados... São Paulo, 2010.

[23] EUROPEAN UNION. THE EUROPEAN PARLIAMENT, on certain components and characteristics of two or three-wheel motor vehicles - 97/24/EC, 17/07/1997.

[24] Ntziachristos, L.; Geivanidis, S.; Samaras, Z.; Xanthopoulos, A.; Steven, H.; Bugsel, B. Study on possible new measures concerning motorcycle emissions. Final report 08.RE.0019.V4. European Commission, September 2009.

[25] BRASIL. MINISTÉRIO DO MEIO AMBIENTE, Resolução CONAMA nº 432. Estabelece novas fases de controle de emissões de gases poluentes por ciclomotores, motociclos e veículos similares novos, e dá outras providências. Publicada no DOU no. 240, de 10 de dezembro de 2003, Seção 1, página 95.

[26] DAEMME, L. C.; PENTEADO, R.; ZOTIM, F. M. Z. Emissão de aldeídos em motociclo flex fuel, abastecido com combustíveis E22, E61 e E100. In: SIMPÓSIO INTERNACIONAL DE ENGENHARIA AUTOMOTIVA - SIMEA, XX, 2012, São Paulo. Trabalhos apresentados... ISSN 2316-4239. São Paulo, 2012.

[27] BOSTEELS, D.; MAY, J.; ETHERIDGE, P.; DE SOUZA, I.; LANCE, D. An investigation into the challenges of achieving future legislative limits over Euro III and WMTC drive cycles for current state of the art motorcycle technologies. SAE International. 2005-01-2156, 2005. 
[28] DAEMME, L. C.; PENTEADO, R.; MELO, T. C. Comparativo entre as metodologias tradicionais de medição de emissões veiculares com a técnica FTIR. In: SIMPÓSIO INTERNACIONAL DE ENGENHARIA AUTOMOTIVA - SIMEA, XX, 2012, São Paulo. Trabalhos apresentados... ISSN 2316-4239. São Paulo, 2012.

[29] LANGTON, A. L.; LI, H.; ANDREWS, G. E. Investigation of aldehyde and VOC emissions during cold star and hot engine operations using $100 \%$ biofuels for a DI engine. SAE International, 2009-01-1515, 2009.

[30] ROBERTS, J. P.; LOWRY, S. R. Modal measurements of some important NMOG species by FT-IR Spectroscopy. International Congress \& Exposition, 940739, Michigan, February 28 March 3, 1994.

[31] HELlER, B.; KLINGENBERG, H.; LACH, G.; WINCKLER, J. Performance of a new system for emission sampling and measurement (SESAM). International Congress and Exposition, 900275, Detroit - Michigan, February 26 - March 2, 1990.

[32] LOWRY, S. R.; ROBERTS, J.; LINDNER, J.; MUNDAY, D. The measurement of exhaust emissions from oxygenated fuel blends by Fourier Transform Infrared Spectroscopy. International Congress and Exposition, 950220, Detroit - Michigan, February 27 - March 2, 1995.

[33] DAEMME, L. C. Estudo da Emissão de Aldeídos em Motociclos. 124f. Dissertação (Mestrado em Desenvolvimento de Tecnologia), PRODETEC, Curitiba, 2012.

[34] R.R. DAVDA, J.W. SHABAKER, G.W. HUBER, R.D. CORTRIGHT, J.A. DUMESIC. Applied Catalysis B: Environmental 56 (2005) 171-186. 